\title{
ANALISIS PENGARUH BRAND IMAGE, BRAND AWARENESS, CORPORATE SOCIAL RESPONSIBILITY DAN SEGMENTASI PASAR PT. XYZ TERHADAP KEPUTUSAN PEMBELIAN
}

\author{
Leonard Marcell \\ Program Studi Magister Manajement Universitas Tarumanagara \\ Leonardmarcell94@gmail.com
}

\begin{abstract}
This study aims to analyze brand image, brand awareness, corporate social responsibility and market segmentation related to purchasing decisions on XYZ products. In this research data collection method used is online questionnaire and offline questionnaire to know the factors sought by customer in choosing product of XYZ. The sample is 130 respondents who consumed XYZ products. Data analysis method used is regression analysis. Based on the result of the research, the results shows that brand awareness, corporate social responsibility and market segmentation have positive and significant influence on purchasing decisions. Brand image has a positive but not significant toward purchasing decision.
\end{abstract}

Keywords: purchase decision, brand image, brand awareness, corporate social responsibility, market segmentation

\section{PENDAHULUAN}

Dalam lingkungan yang relatif konsumtif disertai dengan ketatnya persaingan industri saat ini, menyebabkan industri diharuskan untuk dapat lebih mengembangkan strategi yang unik untuk dapat bersaing dalam memasarkan dan menjual produknya kepada konsumen. Persaingan industri berkembang pesat sejalan dengan perkembangan zaman yang disebabkan kebutuhan manusia yang semakin komplek sebagai akibat semakin banyaknya aktivitas yang dilakukan manusia. Konsumen pada saat ini lebih memilih produk yang praktis dan efisien.

Berdasarkan data dari Ketua umum Asosiasi Perusahaan Air Minum Dalam kemasan Indonesia (Aspadin) bahwa saat ini pemain air minum mineral sekitar 140 perusahaan yang tersebar diseluruh nusantara (Sinar Harapan, 2003). Eksistensi produsen air minum dengan berbagai merek seperti Aqua, Ades, Aquaria, Total, Zam, flash, Viand dan lain-lainnya dari aspek konsumen menunjukkan bahwa konsumen memang menerima akan produk tersebut dalam pemenuhan kebutuhan akan air minum dan dari aspek produsen menjadikan kondisi pasar air minum mineral kental dengan persaingan yang pada akhirnya mengantarkan banyak alternatif produk air mineral yang ditawarkan pada konsumen. Hal ini menunjukkan telah terjadi pergeseran pasar pada produk air minum mineral, dari pasar yang bersifat seller's market dimana hanya ada satu penjual yang dikelilingi banyak konsumen, menjadi pasar yang bersifat buyer's market dimana terdapat konsumen sekarang dikelilingi oleh banyak produsen.

Demikian juga kebutuhan mereka terhadap air minum yang bersih dan higienis yang langsung siap dikonsumsi, sehingga tidak perlu dimasak terlebih dahulu dan tentunya hal ini lebih praktis dan efisien. Dengan adanya keinginan-keinginan dari konsumen tersebut, produsen harus memikirkan bagaimana strategi yang harus dilakukan untuk mendapatkan konsumen.

Setiap perusahaan berlomba melakukan inovasi. Posisinya XYZ sangat kuat disebabkan oleh faktor XYZ sebagai produk air mineral yang pertama kali hadir di Indonesia serta strategi promosi dan pemasaran yang gencar.

Beberapa faktor yang mempengaruhi keputusan pembelian suatu produk yaitu brand image, brand awareness, corporate social responsibility (CSR) dan segmentasi pasar. Keputusan pembelian adalah membeli merek yang paling disukai, tetapi dua faktor bisa 
berada antara niat pembelian dan keputusan pembelian. Menurut Schifman dan Kanuk (2007: 485) keputusan adalah seleksi terhadap dua pilihan alternatif atau lebih. Dengan kata lain, pilhan alternatif harus tersedia bagi seseorang ketika mengambil keputusan. Jika seseorang mempunyai pilihan antara melakuka pembelian atau tidak, orang itu berada dalam posisi mengambil keputusan. Keputusan adalah suatui reaksi terhadap beberapa solusi alternatif yang dilakukan secara sadar dengan menganalisa kemungkinan-kemungkinan dari alternatif tersebut bersama dengan konsekuensinya. Setiap keputusan akan membuat pilihan terakhir, dapat berupa tindakan atau opini. Itu semua bermula ketika kita perlu untuk melakukan sesuatu, tetapi tidak tahu apa yang harus dilakukan.

Kotler dan Keller (2009:189) menyebutkan keputusan pembelian adalah membeli merek yang paling disukai, tetapi dua faktor bisa berada antara niat pembelian dan keputusan pembelian.

\section{POKOK MASALAH}

- Apakah brand image memiliki pengaruh yang signifikan terhadap keputusan pembelian?

- Apakah brand awareness memiliki pengaruh yang signifikan terhadap keputusan pembelian?

- Apakah corporate social responsibility memiliki pengaruh yang signifikan terhadap keputusan pembelian?

- Apakah segmentasi pasar memilki pengaruh yang signifikan terhadap keputusan pembelian?

- Apakah brand image, brand awareness, corporate social responsibility, dan segmentasi pasar secara bersama-sama memiliki pengaruh yang signifikan terhadap keputusan pembelian?

\section{TUJUAN PENELITIAN}

- Untuk melihat apakah brand image berpengaruh signifikan terhadap keputusan pembelian.

- Untuk melihat apakah brand awareness berpengaruh signifikan terhadap keputusan pembelian.

- Untuk melihat apakah corporate social responsibility berpengaruh signifikan terhadap keputusan pembelian.

- Untuk melihat apakah segmentasi pasar berpengaruh signifikan terhadap keputusan pembelian.

- Untuk melihat apakah brand image, brand awareness, corporate social responsibility, dan segmentasi pasar secara bersama-sama memiliki peengaruh yang signifikan terhadap keputusan pembelian.

\section{TINJAUAN PUSTAKA}

- Keputusan Pembelian

Kotler dan Keller (2009:189) menyebutkan keputusan pembelian adalah membeli merek yang paling disukai, tetapi dua faktor bisa berada antara niat pembelian dan keputusan pembelian.

- Brand Image

Kartajaya (2006:373) menjelaskan bahwa citra merek yang terjadi dibenak konsumen tidak selalu sama dengan pesan yang dibawakan iklan bahkan positioning yang diinginkan.

\section{- Brand Awareness}

Durianto dkk (2004:6) menjelaskan bahwa kesadaran (awareness) menggambarkan keberadaan merek di dalam pikiran konsumen, yang dapat menjadi penentu dalam beberapa kategori dan biasanya mempunyai peranan kunci dalam brand equity.

- Corporate Social Responsibility

Menurut Budimanta (2004) Corporate Social Responsibility (CSR) adalah sebuah pendekatan dimana perusahaan mengintegrasikan kepedulian sosial dalam operasi bisnis mereka dan 
interaksi terhadap para pemangku kepentingan yang didasarkan pada prinsip kesuka relaan dan kemitraan kerja.

- Segmentasi Pasar

Philip Kotler oleh Ellen Gunawan (2003:352), menyebutkan bahwa segmentasi pasar adalah usaha untuk memisahkan pasar pada kelompok pembeli menurut jenis-jenis produk tertentu dan bukan barang pemasaran tersendiri.

\section{METODE PENELITIAN}

- Desain Penelitian

Penelitian ini merupakan penelitian deskriptif kuantitatif yang bertujuan untuk menjelaskan suatu fenomena empirisnya yang disertaidata statistik, karakteristik, dan pola hubungan antar variabel. Apabila dilihat dari karakteristiknya, penelitian ini termasuk pada penelitian kausal-komparatif yaitu tipe penelitian dengan karakteristik masalahberupa hubungan sebab akibat antara dua variabel atau lebih.

- Sumber dan Pengumpulan Data

Pengumpulan data yang digunakan dalam penelitian ini adalah:

$>$ Data Primer

Data primer adalah data yang didapatkan dari sumber utama. Dalam penelitian ini metode pengumpulan data yang digunakan adalah metode angket atau kuesioner. Data primer dalam penelitian ini diperoleh dari hasil kuesioner dan wawancara.

Data Sekunder

Menurut Umar (2000), data sekunder adalah data primer yang telah diolah lebih lanjut menjadi bentuk-bentuk seperti tabel, grafik, diagram, gambar, dan sebagainya, sehingga lebih informatif oleh pihak lain.

- Variable Penelitian dan Operasionalisasi Variabel

\section{$>$ Variabel Dependen}

Variabel dependen merupakan variabel yang dipengaruhi oleh variabelvariabel indenpenden. Variabel dependen dalam penelitian ini adalah keputusan pembelian.

$>$ Variabel Indenpenden

Variabel independen merupakan variabel yang dapat menjelaskan variabel dependen. Adapun Variabel indenpenden yang ada pada diatas antara lain:

\section{i. Brand Image}

Citra merek adalah serangkaian keyakinan atau kepercayaan yang dipegang konsumen terhadap suatu produk tertentu.

\section{ii. Brand Awareness}

Kesadaran merek adalah kesanggupan seorang calon pembeli untuk mengenali atau mengingat kembali bahwa suati merek merupakan bagian dari kategori produk tertentu.

\section{iii. Corporate Social Responsibility}

Tanggung jawab moral suatu organisasi bisnis terhadap kelompok yang menjadi stakeholder-nya yang terkena pengaruh baik langsung maupun tidak langsung dari operasi perusahaan.

\section{iv. Segmentasi Pasar}

Segmentasi pasar adalah usaha untuk memisahkan pasar pada kelompok pembeli menurut jenis-jenis produk tertentu dan bukan barang pemasaran tersendiri.

- Metode Analisis

\section{$>$ Uji Asumsi Klasik}

Pengujian asumsi klasik yang akan digunakan dalam penelitian ini adalah: 
$>$ Uji Heteroskedastisitas

Heteroskedastisitas adalah ketidaksamaan variasi variable dan kesalahan yang terjadi yang memperlihatkan hubungan sistematis sesuai dengan besarnya satu atau lebih variable bebas sehingga tidak ada error yang random.

$>$ Uji Normalitas

Uji normalitas dilakukan untuk mengetahui apakah di dalam model regresi variabel dependen dan variabel independen keduanya memiliki distribusi normal atau tidak. Salah satu cara termudah untuk melihat normalitas residual adalah dengan melihat grafik Normal P-P Plot of Regression Standarized Residual yang membandingkan antara data observasi dengan distribusi mendekati distribusi normal.

\section{$>$ Uji Multikolinearitas}

Uji multikolinearitas digunakan untuk mengetahui apakah dalam suatu model regresi terdapat korelasi antar variabel independen. Model regresi yang baik seharusnya tidak terjadi multikoliniearitas diantara variabel independen.

\section{Analisis Regresis Linier Berganda}

Analisis regresi linier berganda dilakukan untuk mengetahui arah hubungan antara variabel independen dengan variabel dependen (Santoso, 2008). Apabila koefisien b bernilai positif (+) maka dapat dikatakan terjadi pengaruh searah antara variabel independen dengan variabel dependen. Setiap kenaikan variabel independen akan mengakibatkan kenaikan variabel dependen. Demikian pula sebaliknya, jika koefisien b bernilai negatif (-), setiap kenaikan variabel independen akan mengakibatkan penurunan variabel dependen.

\section{$>$ Uji Validitas}

Uji validitas dimaksudkan untuk mengetahui sejauh mana alat pengkur benarbenar mengukur apa yang seharusnya diukur (Santoso, 2009: 269). Kriteria pengujian uji validitas adalah:

a. Jika r-hitung positif dan $r$-hitung $>r$ table.

b. Jika r-hitung positif dan $r$-hitung $<\mathrm{r}$ table.

\section{Uji Reliabilitas}

Reliabilitas adalah indeks yang menunjukkan sejauh mana suatu alat pengukur dapat dipercaya atau diandalkan. Bila suatu alat pengukur dipakai dua kali untuk mengukur gejala yang sama dan hasil pengukuran yang diperoleh relative konsisten, maka alat pengukur tersebut reliabel. Dengan sayarat sebagai berikut:

a. Jika a lebih besar sama dengan dari 0,10 maka dinyatakan reliable

b. Jika a lebih kecil dari 0,10 maka dinyatakan tidak reliable

\section{- Hipotesis Statistik dan Pengujiannya}

\section{$>$ Uji Parsial (Uji statistic t)}

Uji t dilakukan pada tingkat keyakinan 95\% dengan ketentuan:

$\mathrm{H} 0$ : Apabila p-value $>0,05$ maka $\mathrm{H0}$ diterima

Ha : Apabila p-value >0,05 maka Ha diterima (Ghozali, 2011:178)

$>\mathbf{U j i} \mathbf{F}$ 
Uji $\mathrm{F}$ dimaksudkan untuk menguji model regresi atas mengaruh seluruh variable indenpenden secara simultan terhadap dependen. Nilai signifikansi kurang dari 0,05 berarti variable indenpenden dapat digunakan untuk memprediksi variable dependen.

$>$ Koefisien Determinasi $\left(\mathbf{R}^{2}\right)$

Nilai koefisien determinasi adalah antara 0 dan 1 . Nilai yang mendekati 1 berarti informasi untuk memprediksi variable dependen sudah hampir diketahui secara keseluruhan.

\section{ANALISIS DAN PEMBAHASAN}

- Deskripsi Statistik

Deskripsi Statistik terdiri dari variable indenpenden: Brand Image, Brand Awareness, Corporate Social Responsibility, dan Segmentasi Pasar. Dengan variable dependen yaitu Keputusan Pembelian.

- Analisis Data

\section{$>$ Uji Heteroskedastisitas}

Uji ini menggunakan grafid Scatterplot terlihat bahwa titik - titik menyebar dengan membentuk pola yang tidak jelas, sehingga dapat disimpulkan bahwa pada model regresi ini tidak terjadi masalah Heteroskedastisitas (Hair, 2010).

\section{$>$ Uji Normalitas}

Uji ini menggunakan grafik Normal P-P Plot of Regression Standarized Residual, yang hasilnya terlihat bahwa titik - titik menyebar di sekitar garis diagonal dan mengikuti garis diagonal, berarti model regresi normal dan layak dipakai untuk memprediksi variabel bebas.

\section{$>$ Uji Multikolinearitas}

Bahwa nilai Tolerance bernilai lebih dari 0,100 dan VIF bernilai kurang dari 10,00, sehingga dapat disimpulkan bahwa pada model regresi tidak terjadi masalah multikolinearitas.

\section{$>$ Analisis Regresi Linear Berganda}

Hasil menunjukkan bahwa nilai signifikansi dari variable Brand Awareness, Corporate Social Responsibility dan Segmentasi Pasar memiliki nilai di bawah $0,05(<0,05)$ dan untuk variabel Brand Image memiliki nilai signifikansi di atas 0,05. Hal ini menunjukkan bahwa variable Brand Awareness, Corporate Social Responsibility dan Segmentasi Pasar berpengaruh positif dan berpengaruh signifikan terhadap Keputusan Pembelian produk XYZ pada level 5\%. Sedangkan untuk variabel Brand Image berpengaruh positif, akan tetapi tidak berpengaruh signifikan terhadap Keputusan Pembelian produk XYZ pada level 5\%. Model regresi yang diperoleh adalah sebagai berikut:

$$
Y=0,453+0,060 X_{1}+0,176 X_{2}+0,509 X_{3}+0,242 X_{4}
$$

Berdasarkan model regresi di atas, dapat dijelaskan sebagai berikut:

- Konstanta sebesar 0,453; artinya jika Brand Image, Brand Awareness, CSR, dan Segmentasi Pasar bernilai 0, maka besarnya Keputusan Pembelian adalah 0,453 .

- Koefisien regresi variabel Brand Image $\left(\mathrm{X}_{1}\right)$ sebesar 0,060; artinya setiap peningkatan Brand Image sebesar satu satuan, maka akan meiningkatkan Keputusan Pembelian sebesar 0,060 satuan, dengan asumsi variabel bebas lainnya bernilai tetap.

- Koefisien regresi variabel Brand Awareness $\left(\mathrm{X}_{2}\right)$ sebesar sebesar 0,176; artinya setiap peningkatan Brand Awareness sebesar satu satuan, maka akan 
meiningkatkan Keputusan Pembelian sebesar 0,176 satuan, dengan asumsi variabel bebas lainnya bernilai tetap.

- Koefisien regresi variabel CSR $\left(\mathrm{X}_{3}\right)$ sebesar sebesar 0,509; artinya setiap peningkatan $C S R$ sebesar satu satuan, maka akan meiningkatkan Keputusan Pembelian sebesar 0,509 satuan, dengan asumsi variabel bebas lainnya bernilai tetap.

- Koefisien regresi variabel Segmentasi Pasar $\left(\mathrm{X}_{4}\right)$ sebesar sebesar 0,242; artinya setiap peningkatan Segmentasi Pasar sebesar satu satuan, maka akan meiningkatkan Keputusan Pembelian sebesar 0,242 satuan, dengan asumsi variabel bebas lainnya bernilai tetap.

\section{$>$ Uji Hipotesa Penelitian}

Uji T

Pengaruh Brand Image terhadap Keputusan Pembelian diketahui dengan menentukan besarnya nilai t tabel pada level 0,05 dan derajat kebebasan ( $\mathrm{df}=$ $\mathrm{n}-1$ ) bernilai 95, sehingga diperoleh nilai t tabel 1,979. Pada Tabel 4.10 Hasi Uji Regresi Linear Berganda diperoleh t hitung untuk variabel Brand Image sebesar 1,694. Bila t hitung > t tabel, maka Ha diterima dan Ho ditolak, hal ini menunjukkan bahwa Brand Image secara parsial tidak berpengaruh signifikan terhadap Keputusan Pembelian produk XYZ.

Pengaruh Brand Awareness terhadap Keputusan Pembelian diketahui dengan menentukan besarnya nilai $\mathrm{t}$ tabel pada level 0,05 dan derajat kebebasan $(\mathrm{df}=\mathrm{n}-1$ ) bernilai 95, sehingga diperoleh nilai t tabel 1,979. Pada Tabel 4.10 Hasi Uji Regresi Linear Berganda diperoleh t hitung untuk variabel Brand Awareness sebesar 3,379. Bila t hitung > t tabel, maka Ha diterima dan Ho ditolak, hal ini menunjukkan bahwa Brand Awareness secara parsial berpengaruh signifikan terhadap Keputusan Pembelian produk XYZ.

Pengaruh Corporate Social Responsibility terhadap Keputusan Pembelian diketahui dengan menentukan besarnya nilai t tabel pada level 0,05 dan derajat kebebasan $(\mathrm{df}=\mathrm{n}-1)$ bernilai 95, sehingga diperoleh nilai t tabel 1,979. Pada Tabel 4.10 Hasi Uji Regresi Linear Berganda diperoleh t hitung untuk variabel Corporate Social Responsibility sebesar 9,122. Bila t hitung < t tabel, maka Ha ditolak dan Ho diterima, hal ini menunjukkan bahwa Corporate Social Responsibility secara parsial berpengaruh signifikan terhadap Keputusan Pembelian produk XYZ.

Pengaruh Segmentasi Pasar terhadap Keputusan Pembelian diketahui dengan menentukan besarnya nilai $\mathrm{t}$ tabel pada level 0,05 dan derajat kebebasan $(\mathrm{df}=\mathrm{n}-1)$ bernilai 95, sehingga diperoleh nilai t tabel 1,979. Pada Tabel 4.10 Hasi Uji Regresi Linear Berganda diperoleh t hitung untuk variabel Segmentasi Pasar sebesar 4,016. Bila t hitung > t tabel, maka Ha diterima dan Ho ditolak, hal ini menunjukkan bahwa Segmentasi Pasar secara parsial berpengaruh signifikan terhadap Keputusan Pembelian produk XYZ.

\section{Uji F}

Seluruh data penelitian untuk seluruh variabel independen secara bersama-sama sudah signifikan.

\section{Koefisien Determinasi $\left(\mathbf{R}^{2}\right)$}

Variabel indenpenden mampu menjelaskan sebesar 0,830 (83\%). Hal ini menunjukkan bahwa variabel dependen (Keputusan Pembelian) dapat dijelaskan oleh variabel independen (Brand Image, Brand Awareness, Corporate Social Responsibility, dan Segmentasi Pasar) sebesar 83\%, sedangkan sisanya sebesar $17 \%$, dipengaruhi oleh variabel lainnya yang tidak diamati dalam penelitian ini. 


\section{KESIMPULAN DAN SARAN}

\section{Kesimpulan}

Berdasarkan hasil penelitian yang telah dilakukan dapat disimpulkan: brand image, brand awareness, corporate social responsibility dan segmentasi pasar secara bersama-sama berpengaruh terhadap keputusan pembelian produk XYZ. Brand awareness, corporate social responsibility, dan segmentasi pasar secara parsial berpengaruh signifikan terhadap keputusan pembelian, akan tetapi brand image tidak berpengaruh signifikan terhadap keputusan pembelian.

\section{Saran}

Peneliti selanjutnya juga dapat menggunakan metode lain dalam meneliti keputusan pembelian, misalnya melalui wawancara mendalam terhadap responden, sehingga informasi yang diperoleh dapat lebih bervariasi dari pada angket yang jawabannya telah tersedia.

\section{DAFTAR PUSTAKA}

Aaker, D. A. (1996). Building strong brands. New York: The Free Press.

Aprizal, Hendri. 2012. Analisis Efektifitas Segmentasi Pasar Terhadap Keputusan Pembelian pada PT Semen Tonasa di Pangkep.

Ardiansyah, Yul. 2013. Pengaruh Kualitas Produk dan Brand Image terhadap Keputusan Pembelian Ulang Air Minum dalam Kemasan Galon Aqua di Kota Padang.

Ariyan, Hendy. 2013. Pengaruh Brand Awareness dan Kepercayaan Konsumen Atas Merek terhadap Keputusan Pembelian Ulang Minuman Aqua di Kota Padang.

Assauri, Sofjan, 2004, Manajemen Pemasaran Konsep dan Strategi, Jakarta: Rajawali Pers.

Budimanta, Arif dkk. (2004). Corporate Social Responsibility: Jawaban Bagi Model Pembangunan Indonesia Masa Kini, Jakarta: ICSD.

Durianto, Darmadi, Sugiarto, \& Lie Joko Budiman. 2004. Brand Equity Ten, Strategi Memimpin Pasar. Jakarta: Gramedia Pustaka Utama.

Fullchis Nurtjahjani, Asminah Rachmi, Masreviatuti. 2017. Pengaruh Segmentasi Pasar Terhadap Keputusan Pembelian Produk Telkom Speedy di PT TELEKOMUNIKASI INDONESIA Cabang Malang.

Kotler, P., dan Keller. 2009. Manajemen Pemasaran. Edisi Ketiga Belas. Jilid Kesatu. Erlangga. Jakarta.

Luviana, Yulian Rifa, M.Hufron, dan Afi Rachmat Slamet. 2016. Pengaruh Green Marketing dan Corporate Social Responsibility terhadap Keputusan Konsumen Membeli Produk Air Minum dalam Kemasan Aqua.

Nursahid. 2000:6. Pengertian CSR. Diakses Maret 2016, diakses dari http://pengertianpengertianinfo.blogspot.co.id/2015/12/pengertiancsr-menurut-ahli.html

Rahma Tiara Hakim. 2013. Pengaruh Persepsi Iklan, Kesadaran Merek, Citra Merek terhadap Sikap pada Merek dan Keputusan Pembelian (Studi pada Produk Pestisida Merek Sidamethrin 50 EC).

Rangkuti, Freddy, 2002. The Power of Brand. Teknik Mengelola Brand Equity dan Starategi Pengembangan Merek. Jakarta : PT. Gramedia Pustaka Umum.

Schiffman, Leon G and Leslie Lazar Kanuk. 2007. Consumer Behavior. Ninth Edition. New Jersey: Prentice Hall.

Setiadi, Nugroho J. 2008. Perilaku Konsumen, Konsep dan Implikasi untuk Strategi dan Penelitian Pemasaran. Jakarta: Kencana.

Simamora, B. 2003. Membongkar Kotak Hitam Konsumen. Gramedia Pustaka Utama. Jakarta.

Susanto, AB dan Himawan Wijanarko, 2004, "Power Branding: Membangun Brand Yang Legendaris", PT.Mizan Pustaka, Bandung. 
Tjiptono, F. 2008. Service Management: Mewujudkan Layanan Prima.Yogyakarta: Andi. Wulan Suciningtyas. 2012. Pengaruh Brand Awareness, brand image, dan media communication terhadap keputusan pembelian. 
